\title{
Novel Analytic Model for the Projected Contact Zone Based on the Flow Line Element Method in Alloyed Bar Rolling
}

\author{
Yonggang Dong, Heng Zhu, Jianfeng Song* \\ College of Mechanical Engineering, Yanshan University, Qinhuangdao, China \\ Email: *songjianfeng@ysu.edu.cn
}

How to cite this paper: Dong, Y.G., Zhu, H. and Song, J.F. (2017) Novel Analytic Model for the Projected Contact Zone Based on the Flow Line Element Method in Alloyed Bar Rolling. Open Access Library Journal, 4: e3247.

http://dx.doi.org/10.4236/oalib.1103247

Received: December 21, 2016

Accepted: January 20, 2017

Published: January 23, 2017

Copyright $\odot 2017$ by authors and Open Access Library Inc.

This work is licensed under the Creative Commons Attribution International License (CC BY 4.0).

http://creativecommons.org/licenses/by/4.0/

\begin{abstract}
For obtaining the profile and the projected area of contact zone exactly during alloyed bar rolling by Round-Oval-Round pass sequence, the analytic model for the length contact and contact boundary curve were built firstly by considering the influence of the spread of the outgoing workpiece on the effective height of outgoing workpiece and roll mean radius, and then the contact surface was discretized by finite flow line elements. Moreover, the radius equation and bite angle equation of different flow lines were derived and they were all expressed as the function of the position angle, then any flow line on the contact surface can be determined since the position angle has been given. Finally, since the analytic equation for the projected area of contact surface was hard to be integrated directly, the analytic model was proposed by summing up the area of discretized parts on the contact surface. Based on the analytical model of contact boundary and flow line element, 3-dimension contact surface was rebuilt by mathematical software, and the validity of analytic model was examined by the bar rolling experiments and the numerical simulation of alloyed bar rolling by rigid-plastic FEM software. Compared with the existing models, the precision of the projecting area of contact zone was improved obviously. So, it can be applied in alloyed bar rolling to predict the projected area of contact zone and velocity of outgoing workpiece exactly.
\end{abstract}

\section{Subject Areas}

Mechanical Engineering

\section{Keywords}

Alloyed Bar, Contact Zone, Projected Area, Round-Oval-Round, Flow Line Element 


\section{Introduction}

Compared with products rolled with the oval-square-oval pass sequence, the bar or rod rolled with round-oval-round pass sequence has a better surface quality and mechanical performance, and the round-oval-round pass sequence is the most common roll pass in bar or rod continuous rolling recently. Since the characteristics of non-uniform distribution of stain, stress and flow velocity on the deformation zone, it is difficult to analyze the process of alloyed bar rolling in oval-square-oval pass sequence accurately [1] [2] [3].

In the past few years, the research on the alloyed bar rolling process was carried out by the simulation methods and experiments. References [4] [5] [6] [7] [8] studied the strain, stress and geometry of deformation zone of bar rolling by the numerical simulation methods based on the FEM software, and references [9] [10] [11] analyzed the effect of roll gap, roll profile and rolling speed on the wear and exit section area by the single-pass rolling and multi-pass rolling experiments and FE analysis. References [12] [13] [14] studied the rolling force and rolling torque of bar rolling and proposed analytic models for estimating the force energy parameters. Because the contact surface between the rolling workpiece and shaped roll is not a cylindrical surface like flat roll rolling but a threedimension curve with complex boundary, the length and boundary of contact surface has to be simplified without taking the spread of rolling workpiece into account for obtaining projected area easily. Based on these simplifications, the geometry and projected area of contact zone were calculated by the conventional equation for billet rolling and the roll force and roll torque was derived on these results, and the results of roll force and roll torque were just an approximate value for bar rolling in round-oval-round pass sequence. Furthermore, the profile of contact boundary and the projected area of contact zone influence the results of velocity field distribution, stress field distribution and strain field distribution directly. Therefore, it is indispensable for analyzing the bar or rod continuous rolling process to determine the profile of contact boundary and the projected area of contact zone exactly.

It is not easy to obtain the precise projecting area of contact zone and the accuracy profile of contact boundary since the contour of contact zone is not regular and difficult to be defined. So, at present the geometry and projected area of contact zone is mostly calculated by the simplified methods, such as the empirical equation [2], the graphical solving method [3].

Shinokura and Takai [15] [16] [17] gave the spread formula and projected area of the deformed workpiece in round-oval-round pass sequence. However, this formula was derived on the base of rolling experiments of plain carbon steel. Y. Lee proposed a mathematical model for predicting the surface profile of deformed workpiece and mean roll radius in Round-Oval-Round pass sequence [18] [19] [20].

The profile of contact boundary and the projecting area of contact zone are correlated to the solution of the rolling force, the velocity field distribution, stress field distribution and strain field distribution directly. So, it is very impor- 
tant to determine the profile of contact boundary and the projected area of contact zone exactly.

\section{The Existing Models for Determining the Projecting Area of Contact Zone}

\subsection{Graphical Solving Method [3]}

As can be seen in Figure 1, the boundary curve of contact zone was simplified as a intersection line between the revolution surface of roll pass and the profile of incoming workpiece, and the intersection line was obtained by linking the intersect in point one by one. So the projection of contact zone was shown as the hatching zone.

\subsection{Analytic Methods Based on the Two Hypothetic Curve Functions for the Contact Boundary}

Shinokura and Takai [15] proposed a formula to estimate the maximum contact length $L$ and projected area $A_{p}$ of contact zone in alloyed bar rolling by ignoring the spread of outgoing workpiece.

The size of oval groove, round groove and corresponding incoming workpiece were shown in Figure 2(a) and Figure 2(b) respectively. The equivalent height of incoming workpiece $\overline{H_{0}}$ and equivalent height of outgoing workpiece $\overline{H_{m 0}}$ were simplified as

$$
\begin{gathered}
\overline{H_{0}}=\frac{A_{0}-A_{s 0}}{2 C_{Z 0}} \\
\overline{H_{m 0}}=\frac{A_{0}-A_{s 0}-A_{h}}{2 C_{Z 0}}=\frac{A_{e 0}}{2 C_{Z 0}}
\end{gathered}
$$

where $A_{0}$ is the section area of incoming workpiece, $A_{s 0}, A_{h}, A_{e 0}$ are the non-effective reduction area, effective reduction area and effective exit section

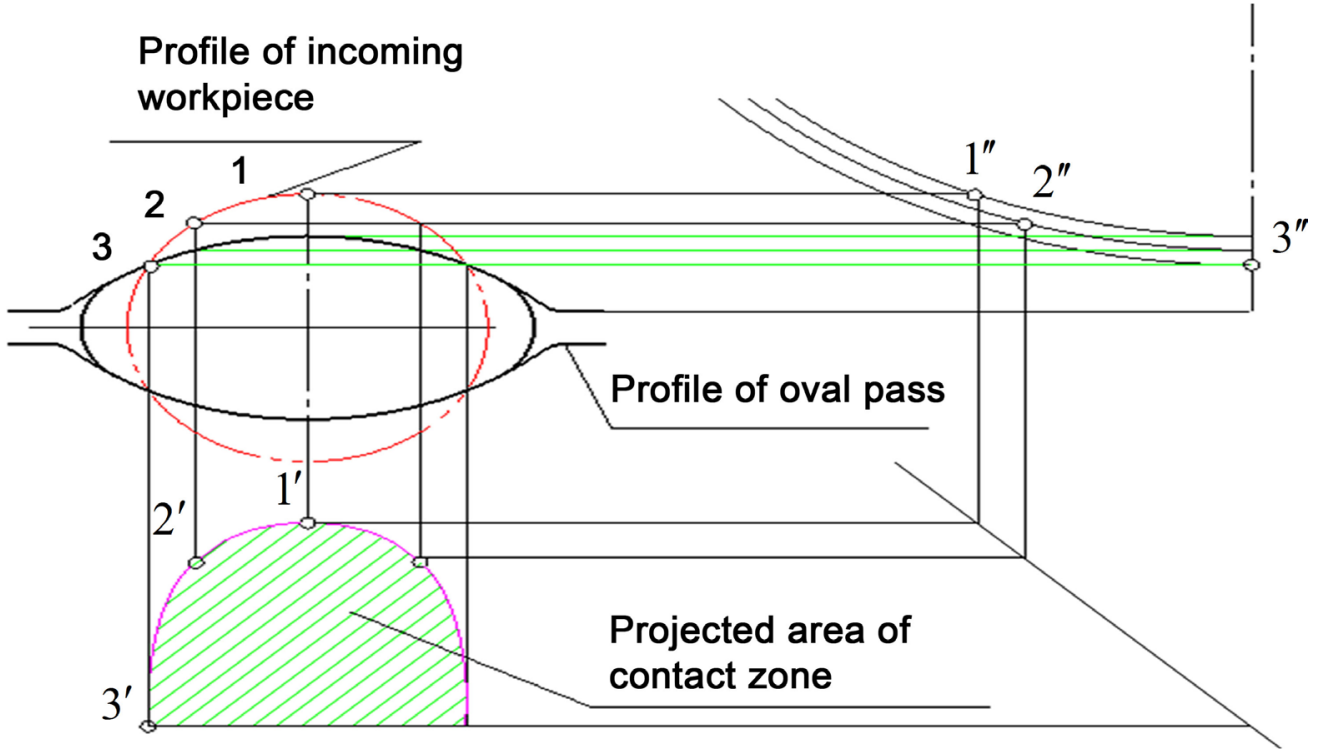

Figure 1. The projected area by a graphical solving method. 




(a)

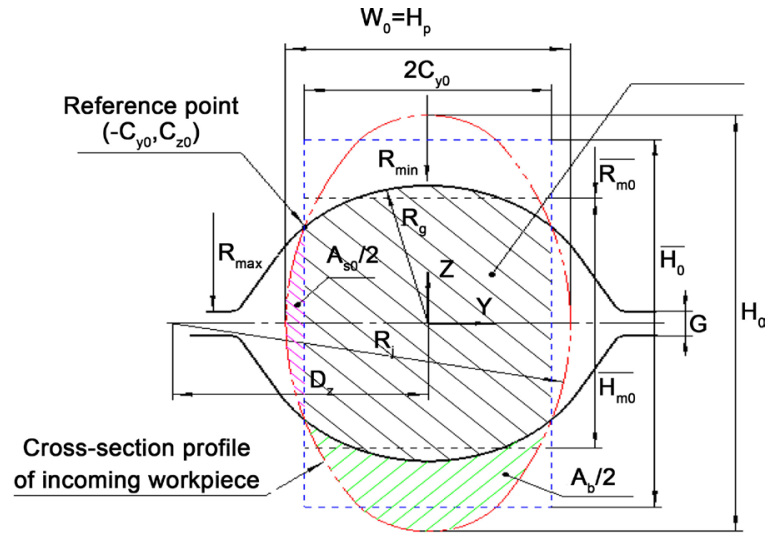

(b)

Figure 2. Definition of pass profile and the incoming workpiece. (a) Round-oval pass; (b) Oval-round pass.

area respectively, $\left(C_{y 0}, C_{z 0}\right)$ is the intersection point between the profile of incoming workpiece and the roll pass.

In round-oval pass rolling, $A_{h}$ and $A_{s 0}$ may be obtained by

$$
\begin{gathered}
A_{h} / 2=\arctan \left(C_{Y 0} / C_{Z 0}\right) \cdot R_{a}{ }^{2}-\left[\int_{-C_{Y 0}}^{C_{Y 0}}\left(\sqrt{R_{1}^{2}-y^{2}}-D_{z}\right) \mathrm{d} y-C_{Y 0} \cdot C_{Z 0}\right] \\
A_{s 0} / 2=\arctan \left(C_{Z 0} / C_{Y 0}\right) \cdot R_{a}-C_{Y 0} \cdot C_{Z 0} \cdot
\end{gathered}
$$

In oval-round pass rolling, $A_{h}$ and $A_{s 0}$ may be given by

$$
\begin{gathered}
A_{h} / 2=\frac{\pi}{8} W_{\max } \cdot H_{p}-\frac{A_{s 0}}{2}-\arccos \left(C_{Z 0} / R_{Y 0}\right) \cdot R_{g}^{2}-C_{Y 0} \cdot C_{Z 0} \\
A_{s 0} / 2=\arcsin \left(C_{Z 0} / R_{1}\right) \cdot R_{1}^{2}-\left(D_{Z}+C_{Y 0}\right) \cdot C_{Z 0}
\end{gathered}
$$

where $R_{1}$ is the radius of the oval groove, $R_{s}$ is the radius of the curvature of the incoming cross-section, $D_{Z}$ is the distance along the Z-axis direction between the origin coordinate

Then the maximum contact length $L_{\max }$ was obtained by

$$
L_{\max }=\sqrt{R_{m 0}\left(\overline{H_{0}}-\overline{H_{m 0}}\right)}=\sqrt{R_{m 0} \frac{A_{h}}{2 C_{Z 0}}}
$$

where $R_{m 0}$ is the mean roll radius at the entrance-section, it can be shown as

$$
R_{m 0}=R_{\min }+\frac{H_{p}}{2}-\frac{\overline{H_{m 0}}}{2} .
$$

For obtaining the projected area of contact zone in alloy bar rolling, Shinokura and Takai expressed the contact boundary curve by the function

$L_{\max } \sqrt{1-\frac{x^{2}}{C_{y}^{2}}}$ according to the empirical data, and the projected area was shown as

$$
A_{p}=\int_{0}^{C_{y}} L_{\max } \sqrt{1-\frac{x^{2}}{C_{y}^{2}}} \mathrm{~d} x=\frac{\pi}{2} L_{\max } C_{y} .
$$

As shown in Figure 2, $C_{y}$ is the coordinate of critical point on the contact boundary along the spread direction. $\left(C_{y}, C_{z}\right)$ is the coordinates of the critical 
point on the contact boundary at the exit-section, and it can be determined by the reference [16] [17].

On the base of Equation (9) Y.lee given another contact boundary curve function $L_{\max }\left(\sqrt{1-\frac{x}{C_{y}}}\right)^{1 / m}$ to modify this equation and the projected area was shown as

$$
A_{p}=\int_{0}^{C_{y}} L_{\max }\left(1-\frac{x}{C_{y}}\right)^{1 / m} \mathrm{~d} x=\frac{3}{2} L_{\max } C_{y}\left(m=\frac{1}{3}\right) .
$$

Moreover, as shown in Equation (9) and Equation (10), two hypothetical functions for indicating the contact boundary curve were given directly without any reasoning and any derivation process. Although the error between the results of two equations are not obvious when the size of rolling workpiece is small enough and then the contact length $L$ and $C_{y}$ is small enough, the absolute error of these two equations will be considerable and it should not be ignored in large diameter bar rolling. So it is not precise enough for these two semi-analytic models to calculate the projected area of multi-pass alloyed bar rolling, then an analytic model should be built to predict the projected area accurately.

In summing up these models for projected area, the Equation (2), which is based on the graphical solving method, does not take the influence of the spread and the contact boundary status of deformed workpiece into account. Therefore, the Graphical solving method can be just used as an estimating value when the spread of deformed workpiece is small enough (Figure 2).

\section{A Novel Analytic Model for the Projected Area of Contact Surface}

\subsection{Modification of Contact Length Model}

As shown in Figure 3, if the spread of outgoing workpiece was not negelected, the effective section area $A_{e}$ and the equivalent width $2 C_{y}$, height $\overline{H_{m}}$ and mean roll radius $R_{m}$ are totally different from the corresponding parameters $A_{e 0}, 2 C_{y 0}, \overline{H_{m 0}}$ and $R_{m 0}$ in Equation (2). $\left(C_{y}, C_{z}\right)$ can be calculated by references [19] [20]. So, the contact length modified as

$$
L_{m}=\sqrt{R_{m}\left(\overline{H_{0}}-\overline{H_{m}}\right)}=\sqrt{\left(R_{\min }+H_{p} / 2-G / 2-\overline{H_{m}} / 2\right)\left(\overline{H_{0}}-\overline{H_{m}}\right)} .
$$

In round-oval pass rolling, the equivalent height of outgoing workpiece was shown as

$$
\begin{aligned}
\frac{\overline{H_{m}}}{2} & =\frac{A_{e}}{4 C_{y}}=\frac{\int_{-C_{y}}^{C_{y}}\left(\sqrt{R_{1}^{2}-y^{2}}-D_{z}\right) \mathrm{d} y}{C_{y}} \\
& =\frac{R_{1}^{2}\left(2 \frac{C_{y}}{R_{1}} \cos \left(\arcsin \frac{C_{y}}{R_{1}}\right)+2 \arcsin \frac{C_{y}}{R_{1}}\right)}{4 C_{y}}-D_{z} .
\end{aligned}
$$

In oval-round pass rolling, the equivalent height of outgoing workpiece was 


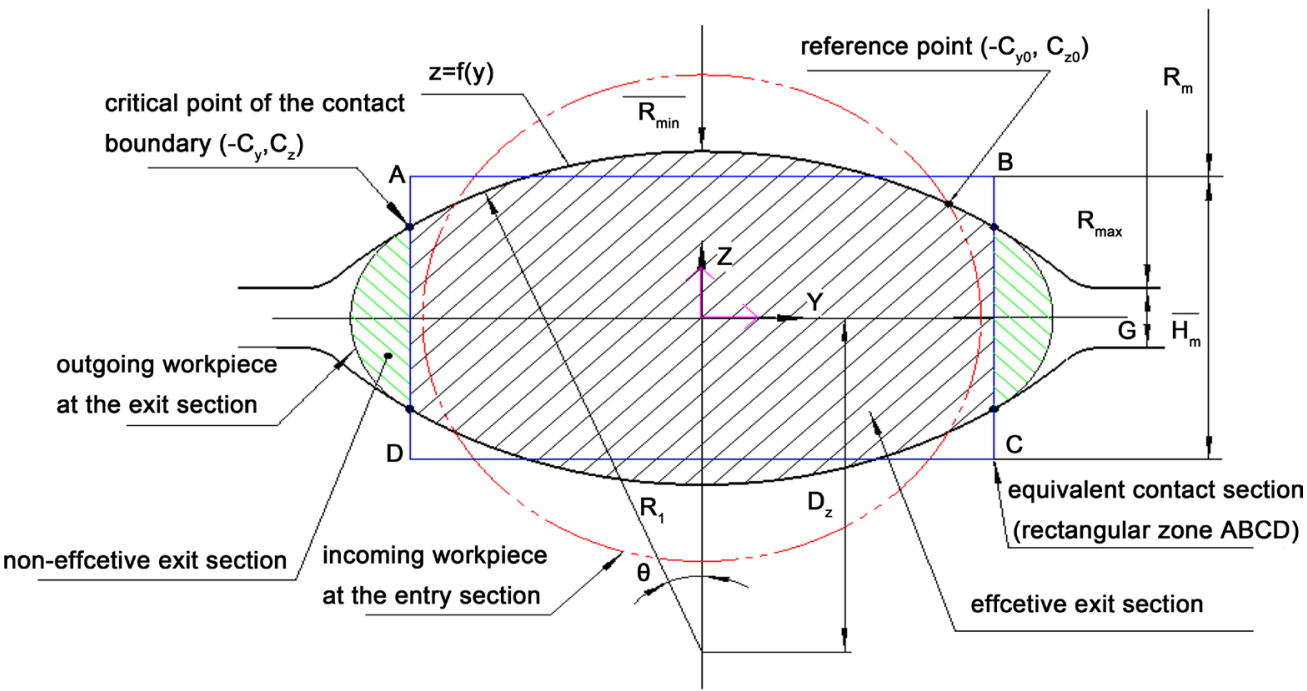

(a)

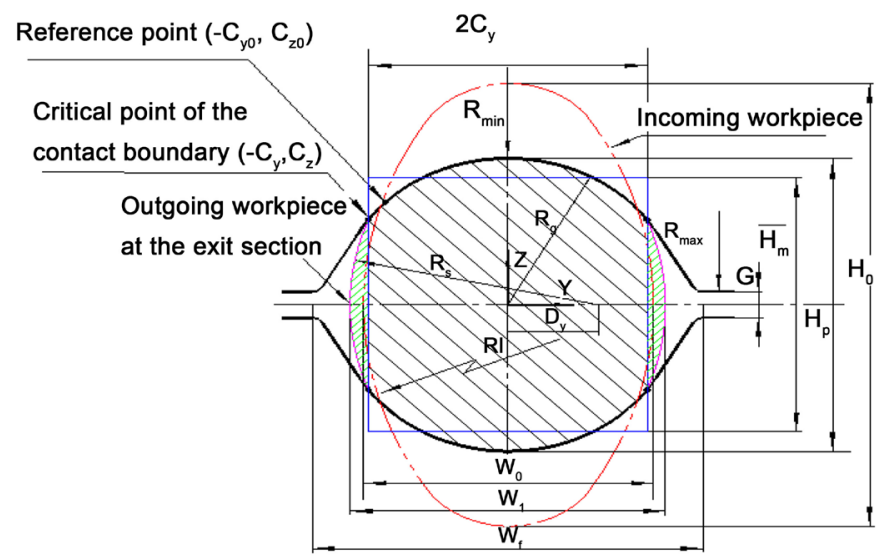

(b)

Figure 3. Parameters in modified model of contact length. (a) Round-oval pass; (b) Oval-round pass.

expressed as

$$
\frac{\overline{H_{m}}}{2}=\frac{A_{e}}{4 C_{y}}=\frac{\arctan \left(C_{y} / C_{z}\right) R_{g}^{2}+C_{y} C_{z}}{C_{y}} .
$$

\subsection{Deformation Zone Geometry and the Boundary of Contact Zone}

As can be seen in Figure 4 and Figure 5, coordinate axes $x, y, z$ are chosen to be the directions of bar length, width and height, respectively, with the origin of the $\mathrm{x}$-axis at the midpoint of the entry plane. The $x-y$ and $x-z$ are plane of symmetry. The curve equation of contact boundary $S$ can be obtained approximately by interpolating between the point $\left(0,0, H_{0}\right)$ and the point $\left(L, C_{y}, C_{z}\right)$. The coordinates of any point on the contact boundary $S$ are shown as $\left(x_{s}, C_{y s}, C_{z s}\right)$.

\subsection{The Definition of the Flow Line and Flow Line Element on the Contact Surface}

The flow plane was defined as a set of eccentric continuous cylindrical surfaces 
having almost straight generators parallel to the roll axis. Assuming that at any cross section along the roll bite the bar height deformation is uniform, the deformation zone was constituted by a set of flow plane, and the contact surface was constituted by a set of flow line element $f_{\alpha}$. The flow line element $f_{\alpha}$ is a set of concentric circular arc with different radius $R$ and different bite angle $\theta_{\alpha s}$, which center is attached on the roll axis. Since the roll radius in the roll pass is different and the height of incoming workpiece is different along the $y$-axis direction, the bite angle $\theta_{\alpha s}$, along the whole contact boundary, is not a constant but a variable which changes with a different position angle $\alpha$ or a different roll radius $R$.



(a)

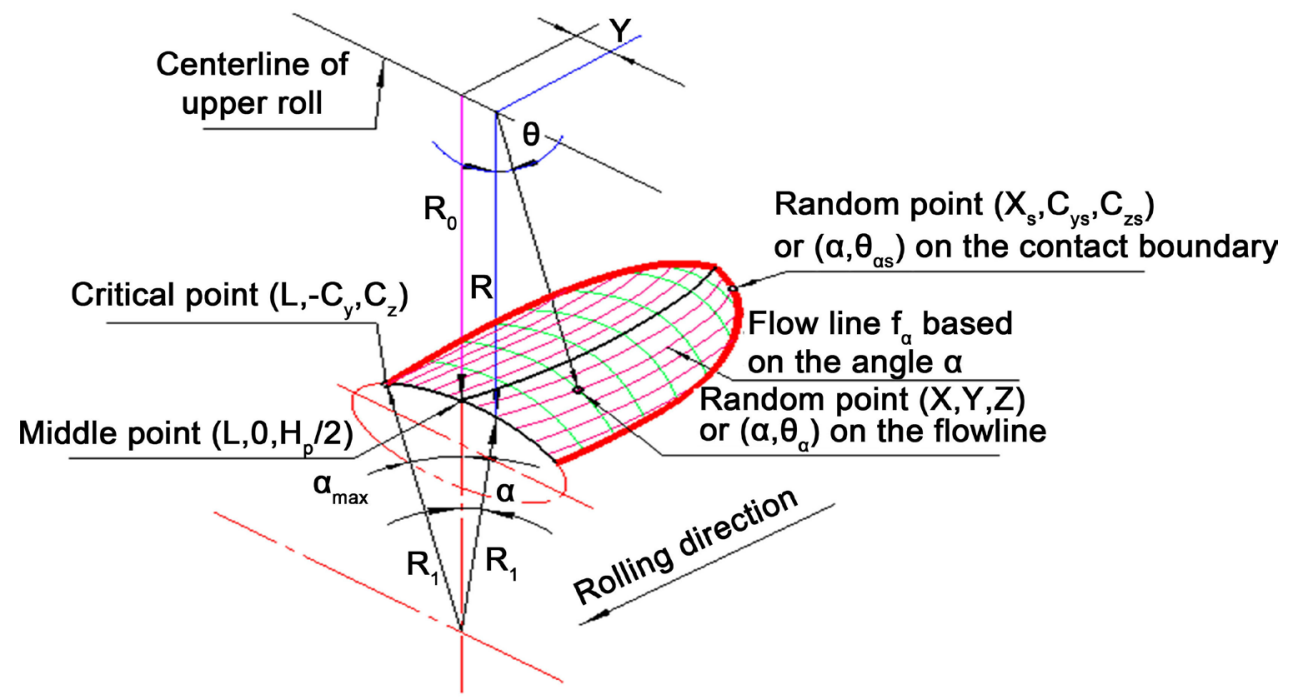

(b)

Figure 4. Geometry and flow line element on the contact surface in oval pass. (a) Geometry of contact surface; (b) Flow line on the contact surface. 


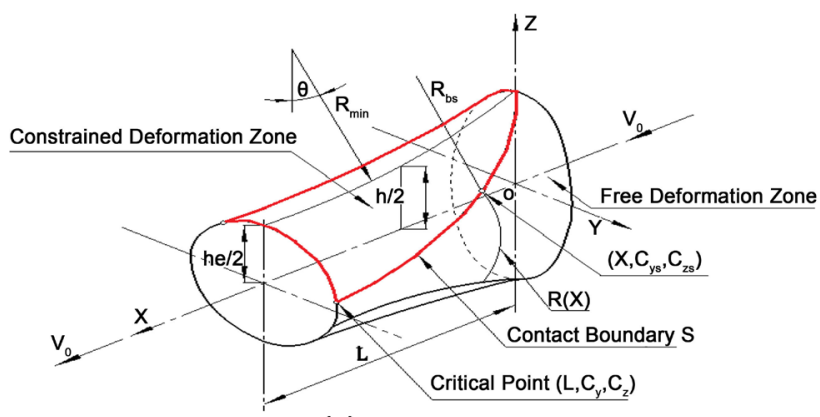

(a)

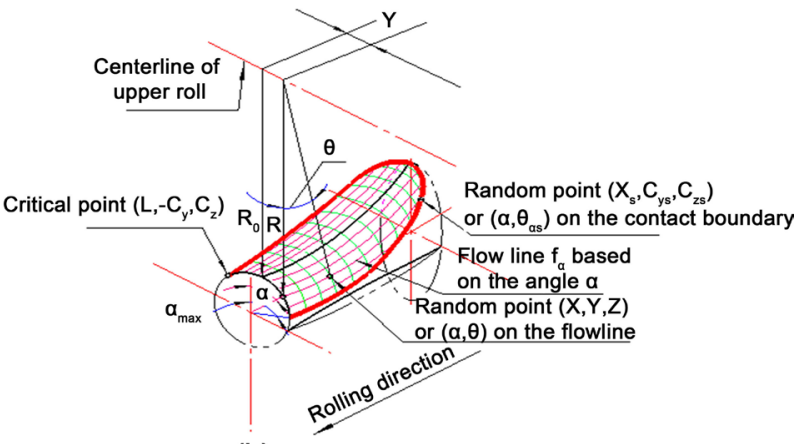

(b)

Figure 5. Geometry and flow line element on the contact surface in round pass. (a) Geometry of contact surface; (b) Flow line on the contact surface.

\subsubsection{The Radius of Flow Line $R$ and the Bite Angle $\theta_{a s}$ in the Round-Oval} Pass Sequence

The radius of flow line $f_{\alpha}$ was expressed as

$$
R=R_{\min }+R_{1}(1-\cos \alpha)\left(0 \leq \alpha \leq \arcsin \frac{C_{y}}{R_{1}} \text { or } 0 \leq \alpha \leq \arccos \frac{C_{z}+D_{z}}{R_{1}}\right) .
$$

The three-dimension coordinates of a random point on the contact surface was shown as

$$
\left\{\begin{array}{l}
x=L-R \sin \theta\left(0 \leq \theta \leq \theta_{\alpha s}\right) \\
y=R_{1} \sin \alpha \\
z=R(1-\cos \theta)+R_{1} \cos \alpha-D_{z}=-R \cos \theta+R_{c}
\end{array} .\right.
$$

On the symmetry plane of deformed workpiece, the position angle $\alpha$ is 0 and the bite angle $\theta_{\alpha s}$ reaches the maximum value $\theta_{\max }$

$$
\theta_{\max }=\arccos \left(1-\frac{H_{0}-H_{p}}{2 R_{0}}\right) .
$$

At the exit section of deformed workpiece, the bite angle $\theta_{\alpha s}$ is 0 and the position angle $\alpha$ reaches the maximum value $\alpha_{\max }$

$$
\alpha_{\max }=\arccos \frac{C_{z}+D_{z}}{R_{1}}
$$

According to the Equation (15), the coordinates of points on the contact boundary was expressed as

$$
\left\{\begin{array}{l}
x_{s}=L-R \sin \theta_{\alpha s} \\
y_{s}=R_{1} \sin \alpha \\
z_{s}=R\left(1-\cos \theta_{\alpha s}\right)+R_{1} \cos \alpha-D_{z}=-R \cos \theta_{\alpha s}+R_{c}
\end{array} .\right.
$$

In the contact zone, the height of the profile at $y=0$ along the $\mathrm{x}$-direction is expressed as

$$
H(x)=H_{0}-\frac{2 L}{R_{0}} x+\frac{1}{R_{0}} x^{2} .
$$

The curve equation of contact boundary $S$ can be obtained approximately by interpolating between the point $\left(0,0, H_{0}\right)$ and the point $\left(L, C_{y}, C_{z}\right)$. The 
coordinate of any point on the contact boundary $S$ is shown as $\left(x, C_{y s}, C_{z s}\right)$, and the coordinate $C_{z s}$ can be shown as

$$
2 C_{z s}=H_{0}-2\left(H_{0}-2 C_{z}\right) \frac{X_{s}}{L}+\left(H_{0}-2 C_{z}\right) \frac{x_{s}^{2}}{L^{2}} .
$$

Substituting the $x_{s}$ of Equation (18) into Equation (20) yields

$$
2 C_{z s}=\left(H_{0}-2 C_{z}\right) \frac{R^{2} \sin ^{2} \theta_{\alpha s}}{L^{2}}+2 C_{z} .
$$

According to the equation $C_{z s}=z_{s}$ and $\sin ^{2} \theta_{\alpha s}=1-\cos ^{2} \theta_{\alpha s}$ yields

$$
\left(H_{0}-2 C_{z}\right) \frac{-R^{2} \cos ^{2} \theta_{\alpha s}}{L^{2}}+2 R \cos \theta_{\alpha s}+\left(H_{0}-2 C_{z}\right) \frac{R^{2}}{L^{2}}-2\left(R_{c}-C_{z}\right)=0 .
$$

Solving the Equation (22) yields

$$
\theta_{\alpha b}=\arccos \frac{L^{2}+L \sqrt{L^{2}+\left(H_{0}-2 C_{z}\right)\left[\left(H_{0}-2 C_{z}\right) \frac{R^{2}}{L^{2}}-2\left(R_{c}-C_{z}\right)\right]}}{R\left(H_{0}-2 C_{z}\right)} .
$$

Substituting Equation (14) into Equation (23) yields

$$
\theta_{\alpha s}=\arccos \frac{L^{2}+L \sqrt{L^{2}+\left(H_{0}-2 C_{z}\right)\left[\left(H_{0}-2 C_{z}\right) \frac{\left(R_{\min }+R_{p}(1-\cos \alpha)\right)^{2}}{L^{2}}-2\left(R_{c}-C_{z}\right)\right]}}{\left(R_{\min }+R_{1}(1-\cos \alpha)\right)\left(H_{0}-2 C_{z}\right)} .
$$

\subsubsection{The Radius of Flow Line $R$ and the Bite Angle $\theta_{\alpha s}$ in the Oval-Round} Pass Sequence

For the oval-round pass sequence, the radius of flow line $f_{\alpha}$ was expressed as

$$
R=R_{\text {min }}+R_{g}(1-\cos \alpha)\left(0 \leq \alpha \leq \arcsin \frac{C_{y}}{R_{g}} \text { or } 0 \leq \alpha \leq \arccos \frac{C_{z}}{R_{g}}\right) .
$$

The three-dimensional coordinates of a random point on the contact surface was shown as

$$
\left\{\begin{array}{l}
x=L-R \sin \theta\left(0 \leq \theta \leq \theta_{\alpha s}\right) \\
y=R_{g} \sin \alpha \\
z=R(1-\cos \theta)+R_{g} \cos \alpha=-R \cos \theta+R_{c}
\end{array} .\right.
$$

On the symmetry plane of deformed workpiece, the position angle $\alpha$ is 0 and the bite angle $\theta_{\alpha s}$ reaches the maximum value $\theta_{\max }$

$$
\theta_{\max }=\arccos \left(1-\frac{H_{0}-H_{p}}{2 R_{0}}\right) .
$$

At the exit section of deformed workpiece, the bite angle $\theta_{\alpha s}$ is 0 and the position angle $\alpha$ reaches the maximum value $\alpha_{\max }$

$$
\alpha_{\max }=\arccos \frac{C_{z}}{R_{g}} .
$$

By the same methods as round-oval pass sequence, the bite angle of oval- 


$$
\begin{gathered}
\text { round pass sequence was } \\
\theta_{\alpha s}=\arccos \frac{L^{2}+L \sqrt{L^{2}+\left(H_{0}-2 C_{z}\right)\left[\left(H_{0}-2 C_{z}\right) \frac{\left(R_{\min }+R_{g}(1-\cos \alpha)\right)^{2}}{L^{2}}-2\left(R_{c}-C_{z}\right)\right]}}{\left(R_{\min }+R_{g}(1-\cos \alpha)\right)\left(H_{0}-2 C_{z}\right)} .
\end{gathered}
$$

\subsubsection{The Projected Area of Contact Zone}

According to definition of projected area of contact zone, it should be calculated by the integral equation as

$$
A_{p}=2 \int_{0}^{\alpha_{\max }} R \sin \theta_{\alpha s} \mathrm{~d} y=2 \int_{0}^{\alpha_{\max }} R \sin \theta_{\alpha s} R_{1} \cos \alpha \mathrm{d} \alpha .
$$

However, it is too complex for Equation (30) to integrate it directly and get a function for projected area. So, the flow line field method based on the discrete law is an effective way to calculate projected area.

Once the position angle of flow line $\alpha$ is given, the roll radius $R$ and the bite angle $\theta_{\alpha s}$ against different position angle of flow line can be determined. Then the space position and the length of any flow line on the contact surface can be obtained. If the whole contact zone was discretized into $\mathrm{n}$ flow lines with different position angle $\alpha_{i}$ and different bite angle $\theta_{\alpha s i}$, the arc length of any flow line was expressed as

$$
L_{f i}=R_{i} \theta_{\alpha s i}=f\left(\alpha_{i}\right) \quad(0 \leq i \leq n) .
$$

The position angle of $i$ th flow line can be shown as

$$
\alpha_{i}=\frac{i}{n} \alpha_{\max }(0 \leq i \leq n) .
$$

The projected length of this flow line on plane xoy can be obtained by

$$
L_{p i}=R_{i} \sin \theta_{\alpha s i} \quad(0 \leq i \leq n) .
$$

Substituting Equation (32) into Equation (14), Equations ((24), (25) and (29)) to replace the position angle $\alpha$ can yield $R_{i}$ and $\theta_{\alpha s i}$ in oval pass rolling and round pass rolling respectively, then the projected area of contact zone on the plane xoy can be shown as

$$
A_{p}=2 \int_{0}^{\alpha_{\max }} R \sin \theta_{\alpha s} \mathrm{~d} y=\sum_{i=0}^{n}\left(R_{i} \sin \theta_{\alpha s i}\right) \frac{C_{y}}{n} .
$$

\section{Results and Discussions}

The alloyed bar rolling experiments had been accomplished in BEIMAN SPICIAL STEEL CO. LTD, the round workpiece of diameter $171 \mathrm{~mm}$ were rolled in one oval pass and one round pass of 22-stand Pomini Rolling Mill. The deformation zone of rolling workpices was obtained by stopping the rolling process when the workpiece was rolled in the oval pass and round pass simultaneously. The rolling schedule is shown as Table 1 . The material is structural alloyed steel $41 \mathrm{Cr} 4$. The dimension of the groove schedule is respectively shown as Figure 6(a) and Figure 6(b).

As can be seen in Table 2, the parameters for calculating the projecting area of 
Table 1. Rolling schedule of the Pomini Rolling Mills.

\begin{tabular}{cccccccc}
\hline Parameter & $\begin{array}{c}\text { Roll diameter } \\
(\mathrm{mm})\end{array}$ & $\begin{array}{c}\text { Bite angle } \\
(\text { degree })\end{array}$ & $\begin{array}{c}\text { Motor speed } \\
(\mathrm{rpm})\end{array}$ & $\begin{array}{c}\text { Roll speed } \\
(\mathrm{rpm})\end{array}$ & $\begin{array}{c}\text { Roll gap } \\
(\mathrm{mm})\end{array}$ & $\begin{array}{c}\text { Height of incoming workpiece } \\
(\mathrm{mm})\end{array}$ & $\begin{array}{c}\text { Maximum Height of roll } \\
\text { pass }(\mathrm{mm})\end{array}$ \\
\hline Oval pass & 730 & 24.8 & 822 & 7.8 & 20 & 171 & 112 \\
Round pass & 730 & 28 & 887 & 10.1 & 12 & 197.6 & 136 \\
\hline
\end{tabular}

Table 2. The parameters for calculating the projecting area.

\begin{tabular}{lcccccccccccccc}
\hline & \multicolumn{10}{c}{$(\mathrm{mm})$} \\
Parameters & \multicolumn{1}{c}{$A_{0}$} & $A_{s 0}$ & $A_{h}$ & $A_{e 0}$ & $A_{e}$ & $\overline{H_{m 0}}$ & $\overline{H_{m}}$ & $\overline{H_{0}}$ & $\left(C_{y 0}, C_{z 0}\right)$ & $\left(C_{y}, C_{z}\right)$ & $R_{m 0}$ & $R_{\min }$ & $R_{m}$ \\
\hline Oval pass & $22,965.83$ & 747.89 & 6796.77 & $15,421.17$ & $17,274.3$ & 99.22 & 93.08 & 142.95 & $(77.71,35.66)$ & $(92.65,25.95)$ & 325.39 & 319 & 328.46 \\
Round pass & $17,684.15$ & 914.81 & 4697.9 & $12,071.44$ & $13,409.19$ & 123.05 & 117.77 & 170.94 & $(49.05,47.1)$ & $(56.93,37.19)$ & 309.17 & 303 & 312.31 \\
\hline
\end{tabular}

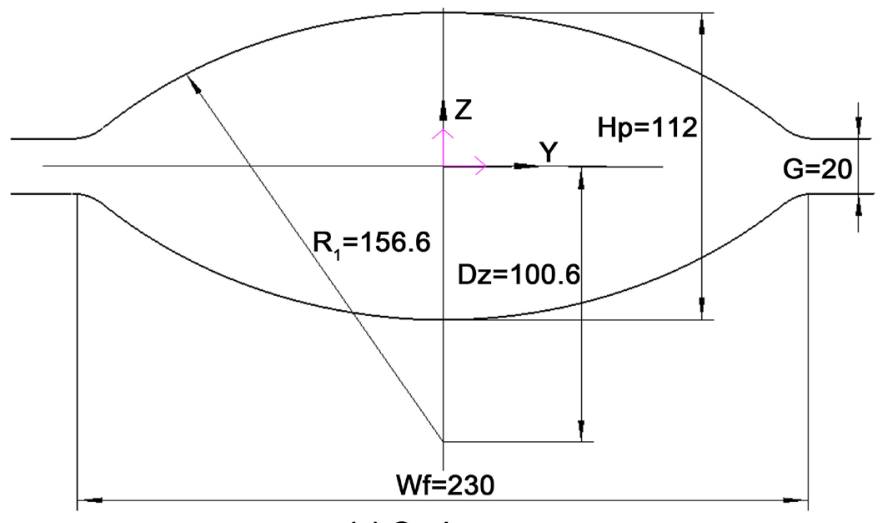

(a) Oval pass



(b) Round pass

Figure 6. The dimension of the groove schedule. (a) Oval pass (b) Round pass.

$(\mathrm{Cy}, \mathrm{L})$

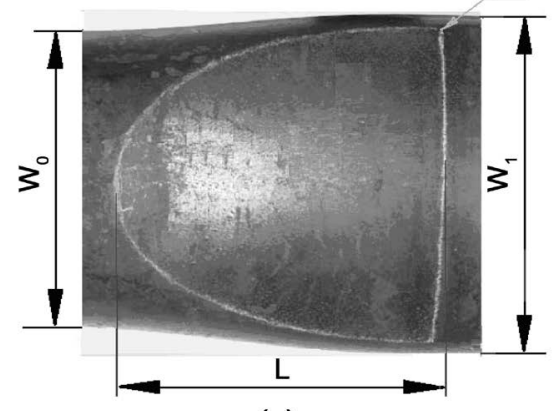

(a)

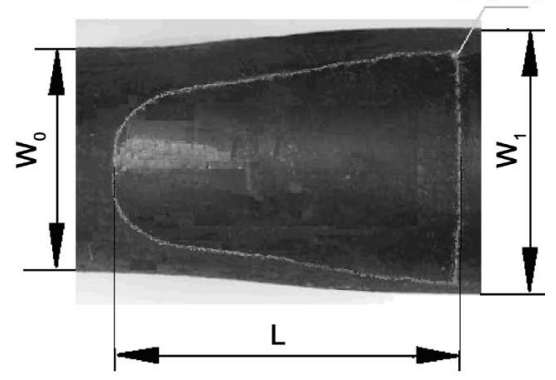

(b)

Figure 7. Profile of the curve on the contact boundary. (a) Oval-pass; (b) Round-pass.

contact zone were listed one by one.

As shown in Figure 7(a) and Figure 7(b), the profile of curve on the contact boundary in oval pass and round pass were measured and distinguished by a white chalk.

As shown in Figure 8, the contact boundary and the contact surface were obtained by the rigid-plastic FEM software DEFORM5.03. Moreover, the surface profile of incoming workpiece and outgoing workpiece in oval pass and round pass was shown as Figure 9. 




Figure 8. Contact boundary and contact zone in oval pass rolling.

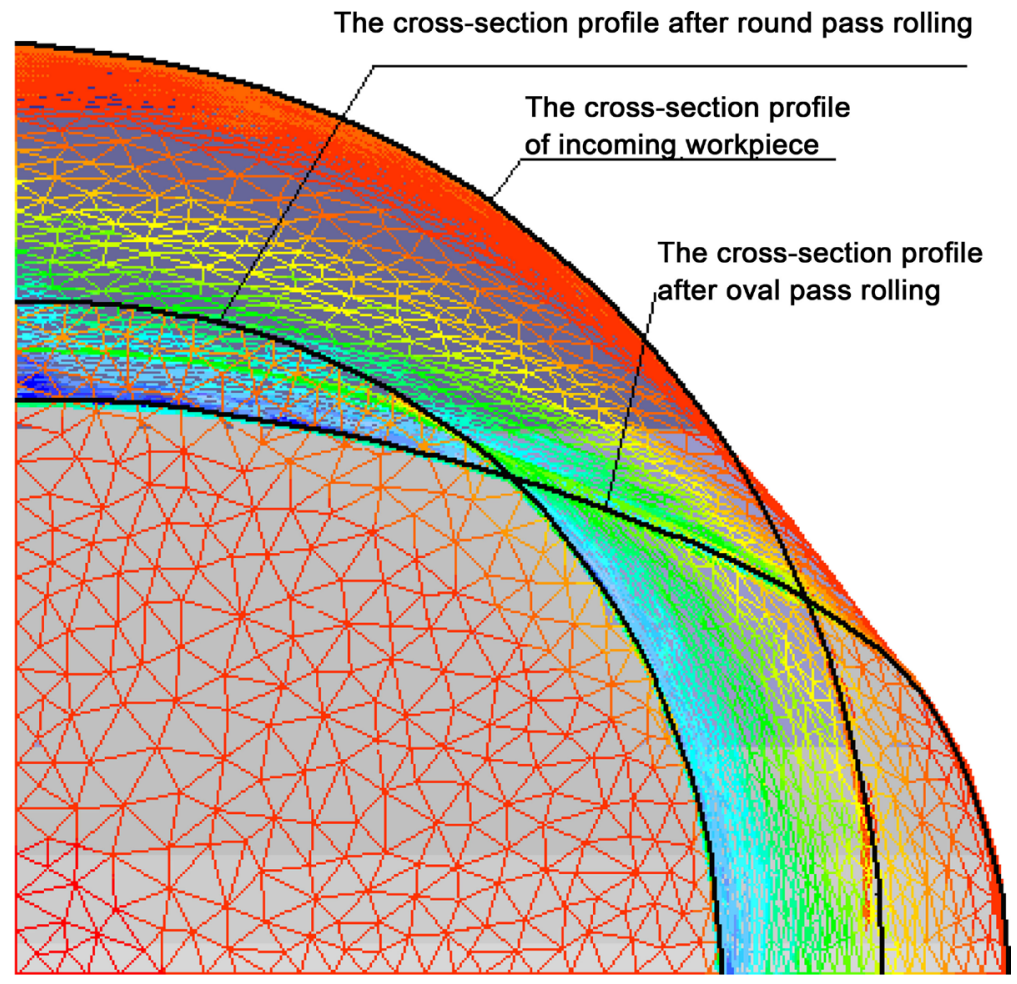

Z

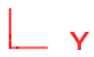

Figure 9. Surface profile of incoming workpiece and outgoing workpiece. 
As can be seen in Figure 10(a) and Figure 10(b), the 3-dimension contact surface and contact boundary were rebuilt by Matlab 7.0 according to the novel analytic model of contact boundary and contact surface. In Figure 11, the contact boundary from the novel analytic model was compared with that of experimental data and simulation result.

Results of contact length and projected area from the novel model, the calculating results from the existing models, the experimental data and the simulation results were all listed in Table 3 . As shown in Table 3 , the results of contact length and projected area from different models were listed and compared with corresponding experimental data and simulation results. The results of contact length from the modified analytic model are less than that of empirical formula and the graphical solution, and it is greater than that of Shinokura formula and Y. Lee formula. Moreover, the error of contact length from the modified model is less than that of existing models.

Since the outgoing workpiece of oval pass rolling will be rolled in next round pass as an incoming workpiece and the section profile at the exit of oval pass influence the contact surface of round pass rolling greatly, the prediction error of round pass is obviously greater than the prediction error of oval pass. Moreover,

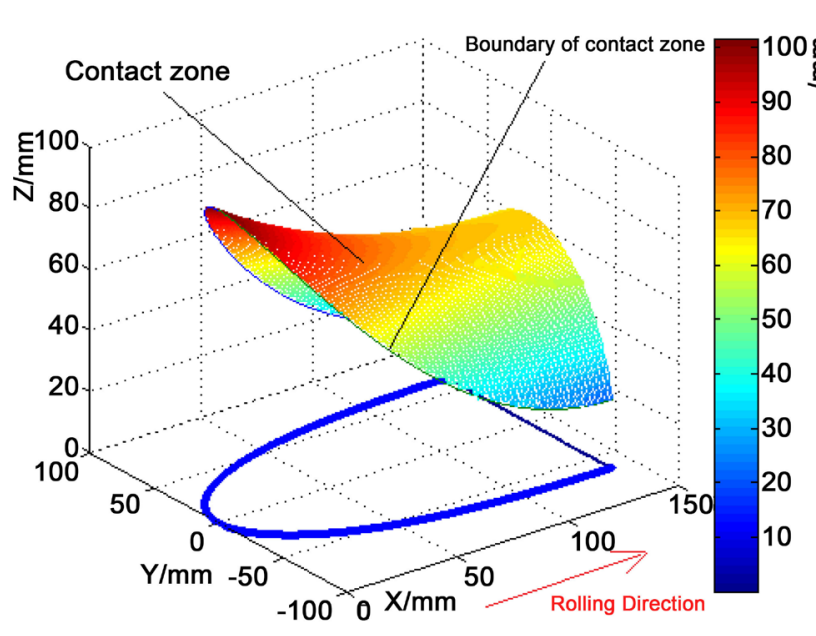

(a)

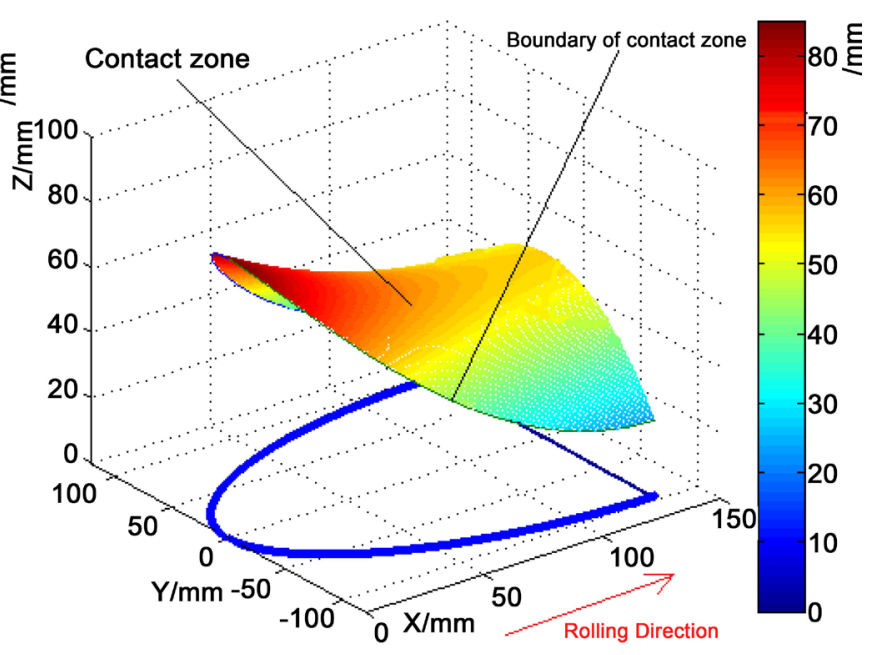

(b)

Figure 10. Rebuilt contact surface based on analytic model by Matlab7.0. (a) Oval-pass; (b) Round-pass.

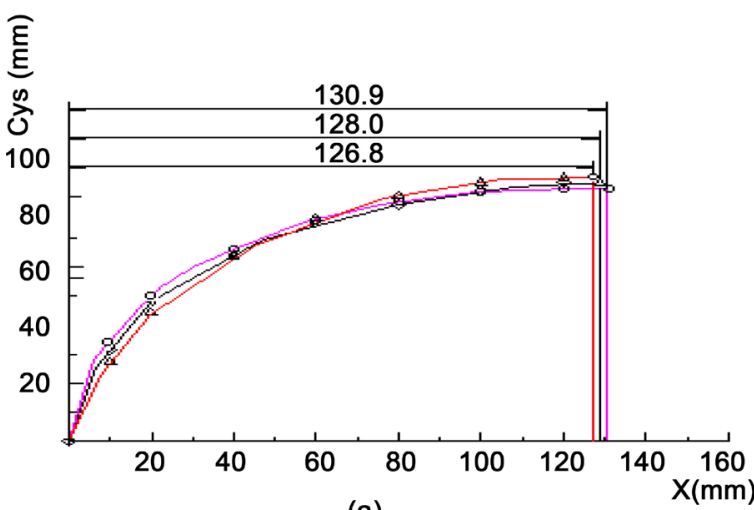

(a)

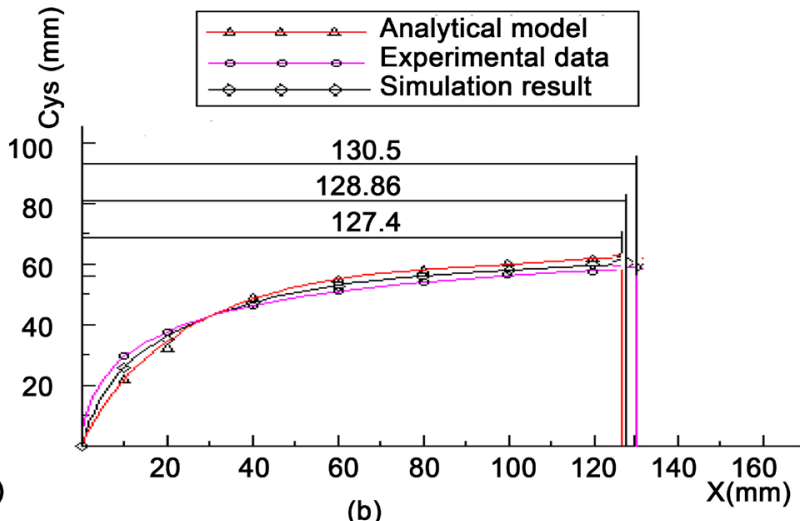

(b)

Figure 11. Profile of the curve on the contact boundary. (a) Oval-pass; (b) Round-pass. 
Table 3. Results of different models.

\begin{tabular}{cccccc}
\hline & $\begin{array}{c}\text { Parameter } \\
\text { Pass }\end{array}$ & $\begin{array}{c}\text { Length of } \\
\text { contact zone } \\
(\mathrm{mm})\end{array}$ & $\begin{array}{c}\text { Error of } \\
\text { contact } \\
\text { length }(\%)\end{array}$ & $\begin{array}{c}\text { Projected area of } \\
\text { contact zone } \\
\left(\mathrm{mm}^{2}\right)\end{array}$ & $\begin{array}{c}\text { Error of } \\
\text { projected area } \\
(\%)\end{array}$ \\
\hline & Graphical solution & 132.8 & +1.45 & $16,635.0$ & -9.98 \\
& Shinokura Formula & 119.3 & -8.86 & $17,351.9$ & -6.10 \\
Oval & Y. Lee Formula & 119.3 & -8.86 & $17,222.5$ & -6.80 \\
& Novel model & 128.0 & -2.22 & $18,035.4$ & -2.40 \\
& Experimental results & 130.9 & 0 & $18,478.6$ & 0 \\
& Simulating results & 126.8 & -3.13 & $17,763.4$ & -3.87 \\
& Graphical solution & 133.1 & +1.99 & $10,225.0$ & -14.14 \\
& Shinokura Formula & 121.7 & -6.74 & $10,877.5$ & -8.66 \\
& Y.Lee formula & 121.7 & -6.74 & $10,392.6$ & -12.73 \\
pass & Novel model & 128.9 & -1.23 & $12,312.3$ & +3.39 \\
& Experimental results & 130.5 & 0 & $11,908.8$ & 0 \\
& Simulating result & 127.4 & -2.38 & $11,456.6$ & -3.80 \\
\hline
\end{tabular}

results of projected area from the novel analytic model approaches the experimental data and simulation results very well, and its error is less than any existing models.

\section{Conclusions}

1) The contact boundary is a complex 3-dimension curve, and its profile is not only concerned with the parameters of pass profile $R_{1}, R_{\mathrm{g}}, R_{\min }, G, D_{\mathrm{z}}$ and the shape parameters of incoming workpiece $H_{0}, R_{\mathrm{a}}$, but also influenced by the coordinates of critical point $\left(C_{Y}, C_{Z}\right)$;

2) The modified contact length model is rational because the influence the effective section area of the outgoing workpiece $A_{\mathrm{e}}$, the critical point $\left(C_{Y}, C_{Z}\right)$ on the contact boundary, the effective height of outgoing workpiece $\overline{H_{m}}$ and the mean roll radius $R_{m}$, has been taken into account in this model;

3) Based on the different position angle $\alpha$ and bite angle $\theta_{\alpha s}$, the flow line element discretizes the complicated 3-dimension contact surface conveniently and makes it easier to rebuild the contact surface, and it is a good way to analyze the non-uniform stress and strain distribution accurately;

4) The discretizing and summing up method is an efficient way to solve the projected area, and results from this method approach the experimental data and simulating results very well.

\section{References}

[1] Xu, C. (2009) The Pass Design of Structural Sections. Chemistry Industry Press, Beijing, 79. (In Chinese)

[2] Hu, B. (2010) The Pass Design of Structural Sections. Metallurgical Industry Press, Beijing, 31-39. (In Chinese) 
[3] Yuan, Z.-X. and Wang, S.-P. (2008) The Plastic Deformation and Rolling Fundamentals. Metallurgical Industry Press, Beijing, 211-213. (In Chinese)

[4] Inoue, T., Torizuka, S. and Nagai, K. (2005) Novel Rod Rolling Process for Designing Efficiently Ultrafine-Grained Steel Bars Based on Numerical Analysis. Journal of the Japan Institute of Metals, 69, 934-942. https://doi.org/10.2320/jinstmet.69.934

[5] Milenin, A.A., Dyja, H. and Mroz, S. (2004) Simulation of Metal Forming during Multi-Pass Rolling of Shape Bars. Journal of Materials Processing Technology, 153, 108-114.

[6] Aksenov, S.A., Chumachenko, E.N., Logashina, I.V., et al. (2015) Numerical Simulation in Roll Pass Design for Bar Rolling. Metalurgija, 54, 75-78.

[7] Graf, M. and Kawalla, R. (2010) Simulation System for Fast Analysis of Multistage Hot Rolling Processes Strip and Rod/Wire. Steel Research International, 81, 122125.

[8] Nekrasov, I.I., Karamyshev, A.P., Parshin, V.S., et al. (2011) Studies of the Rolling of Ribbed Bars Using the Deform Software Package. Metallurgist, 55, 167-170. https://doi.org/10.1007/s11015-011-9408-4

[9] Park, H.S. and Lee, Y. (2008) Experimental Study for Roll Gap Adjustment due to Roll Wear in Single-Stand Rolling and Multi-Stand Rolling Test. Journal of $\mathrm{Me}$ chanical Science and Technology, 22, 937-945.

[10] Byon, S.M., Na, D.H. and Lee, Y. (2009) Effect of Roll Gap Adjustment on Exit Cross Sectional Shape in Groove Rolling-Experimental and FE Analysis. Journal of Materials Processing Technology, 209, 4465-4470. https://doi.org/10.1016/j.jmatprotec.2008.10.045

[11] Lee, Y. (2007) Effect of Rolling Speed on the Exit Cross Sectional Shape in Rod Rolling Process. International Journal of Precision Engineering and Manufacturing, 8, 27-31.

[12] Ragab, A.R. and Samy, S.N. (2006) Evaluation of Estimates of Roll Separating Force in Bar Rolling. Journal of Manufacturing Science and Engineering-Transactions of the ASME, 128, 34-45. https://doi.org/10.1115/1.2120779

[13] Deng, W., Zhao, D.-W., Qin, X.-M., et al. (2010) Linear Integral Analysis of Bar Rough Rolling by Strain Rate Vector. Journal of Iron and Steel Research International, 17, 28-33. https://doi.org/10.1016/S1006-706X(10)60068-4

[14] Lee, Y. and Kim, Y.H. (2001) Approximate Analysis of Roll Force in a Round-OvalRound Pass Rolling Sequence. Journal of Material Processing Technology, 113, 124 130. https://doi.org/10.1016/S0924-0136(01)00712-9

[15] Shinokura, T. and Takai, K. (1986) Mathematical Model of Roll Force and Torque in Steel Bar Rolling. Tetsu-To-Hagane, 72, 58-64. (In Japanese)

[16] Lee, Y. and Choi, S. (2000) New Approach for the Prediction of Stress Free Surface Profile of a Workpiece in Rod Rolling. ISIJ International, 40, 624. https://doi.org/10.2355/isijinternational.40.624

[17] Lee, Y., Choi, S. and Kim, Y.H. (2000) Mathematical Model and Experimental Validation of Surface Profile of a Workpiece in Round-Oval-Round Pass Sequence. Journal of Materials Processing Technology, 108, 87. https://doi.org/10.1016/S0924-0136(00)00734-2

[18] Lee, Y. (2001) An Analytical Study of Mean Roll Radius in Rod Rolling. ISIJ International, 41, 1414. https://doi.org/10.2355/isijinternational.41.1414

[19] Dong, Y.G., Zhang, W.Z. and Song, J.F. (2008) An Analytical Model for the Prediction of Cross-Section Profile and Mean Roll Radius in Alloy Bar Rolling. Journal of University of Science and Technology Beijing, 15, 344-351. 
https://doi.org/10.1016/S1005-8850(08)60065-1

[20] Dong, Y.G., Zhang, W.Z. and Song, J.F. (2006) A New Analytical Model for the Calculation of Mean Roll Radius in Round-Oval-Round Alloy Bar Rolling. ISIJ International, 46, 1458-1466. https://doi.org/10.2355/isijinternational.46.1458

Submit or recommend next manuscript to OALib Journal and we will provide best service for you:

- Publication frequency: Monthly

- 9 subject areas of science, technology and medicine

- Fair and rigorous peer-review system

- Fast publication process

- Article promotion in various social networking sites (LinkedIn, Facebook, Twitter, etc.)

- Maximum dissemination of your research work

Submit Your Paper Online: Click Here to Submit

Or Contact service@oalib.com 